\title{
Development of the 'SNS Older Adults measure' (SNS-OA) to examine social network site use in older adults
}

Loveday Newman ${ }^{1 \mathrm{~A}}$, Charlotte Stoner ${ }^{1}$, Anne Corbett $^{2}$, Maria Megalogeni ${ }^{3}$, Zunera Khan $^{3} \&$ Aimee Spector ${ }^{1}$

1 = Department of Clinical, Educational and Health Psychology, University College London, 119 Torrington Place, London, WC1E 7HB

$2=$ Institute of Health Research, University of Exeter Medical School, St Luke's Campus, University of Exeter, Exeter EX1 2LU

3 = Department of Old Age Psychiatry, Institute of Psychiatry, Psychology and Neuroscience, Denmark Hill Campus, King's College London, London, SE5 8AF

$$
\text { A }=\text { Corresponding Author, Email: }
$$

loveday.newman.13@ucl.ac.uk/loveday.newman@.cpft.nhs.uk

\section{Acknowledgements}

The authors thank the National Institute for Health Research (NIHR) Mental Health Biomedical Research Centre at South London and Maudsley NHS Foundation Trust, Institute of Psychiatry, King's College London and Collaboration for Leadership in Applied Health Research and Care South West Peninsula for supporting this research. The views expressed are those of the author(s) 
and not necessarily those of the NHS, the NIHR or the Department of Health. Thank you to Robert Stenton for all his help with web development.

\section{Funding}

This work was supported by National Institute for Health Research (NIHR) Maudsley Biomedical Research Centre.

\section{Disclosure of Interest}

The authors report no conflict of interest. 


\section{$\underline{\text { Abstract }}$}

\section{$\underline{\text { Objectives }}$}

Social Networking Sites (SNSs) may ameliorate loneliness in later life but no measure of SNS use for this population exists. This study describes the development of the 'SNS Older Adults measure' (SNS-OA), to improve understanding of older adults' SNS use and its relationship to social wellbeing.

\section{Methods}

The SNS-OA underwent initial development, including literature reviews and consultation with target population $(n=9)$ and experts $(n=9)$; piloting $(n=74)$, and evaluation of psychometric properties $(n=263)$.

\section{$\underline{\text { Results }}$}

The final measure comprised three 'motive' scales (using SNSs to maintain close ties, maintain and strengthen weaker ties and diversion), and two 'affect' scales (positive/negative). Whilst many items were weakly endorsed by participants, the measure demonstrated good reliability (Cronbach $\alpha=0.85 ;$ ICC $=0.82$ ) and some convergent validity, with some subscales correlating with a personality measure in hypothesised directions. No statistically significant correlations were observed between the measure and social wellbeing.

\section{$\underline{\text { Conclusions }}$}

Despite the measure's limitations, this research has enabled a better understanding of SNS use in older adults and has important implications for research in this area. Findings also suggest a complex relationship between social wellbeing and SNS use in later life. 
Keywords: social networking sites, technology, social wellbeing, loneliness, measure development.

\section{$\underline{\text { Introduction }}$}

Social Networking Sites (SNSs) are now being widely adopted by older adults (here considered as adults aged $65+$ ). Approximately $30 \%$ of adults aged $65+$ used SNSs in 2015, an increase of $19 \%$ from 2010 (OfCom, 2016). Older adults primarily use SNSs to keep in touch with family and close friends (Jung \& Sundar, 2016; Jung, Walden, Johnson \& Sundar, 2017). However, some older adults perceive SNSs as a non-meaningful way to spend time or see it as detracting from their primary interest in nurturing close relationships (Hope, Schwaba, \& Piper, 2014; Lüders \& Brandtzaeg, 2014).

SNSs are: (1) built on Web 2.0 (characterised by the change from static web pages to usergenerated, dynamic content); (2) underpinned by user-generated content; (3) facilitate the development of online connections to other individuals and/or groups; and (4) users create profiles designed and maintained by the site (Obar \& Wildman, 2015). Because of their accessibility, convenience and potential for overcoming spatial barriers to connecting with others, it has been suggested that SNSs could play a part in reducing social isolation and loneliness in later life (Campos et al., 2016).

Social relationships are important for wellbeing and health (Umberson \& Montez, 2010). In later life, factors such as physical morbidity and bereavement can lead to increased risk for social isolation and loneliness (Victor, Scambler, Bowling, \& Bond, 2005). Although loneliness exists across the lifespan, 5-15\% of adults aged $65+$ report 'frequent', and $20-40 \%$ report 'occasional', loneliness. Amongst adults aged $80+$, loneliness rates increase, with $40-50 \%$ of adults in this age group saying they are 'often' lonely (Dykstra, 2009). 
Interventions designed to increase participation in computer and Internet based activities as a means of reducing loneliness and social isolation in older adults have been developed, with mixed evidence for effectiveness (Chipps, Jarvis, \& Ramlall, 2017). However, a lack of methodological rigour across studies (Chipps et al., 2017), and the heterogeneous nature of computer and Internet based interventions suggest more research is needed to understand their role in older adults' social wellbeing.

Research examining SNS use in adolescent and younger adults suggests that 'active' use of SNSs (e.g. content creation, online chatting), and use of SNSs to maintain friendships, improves social wellbeing, while 'passive' use and using it to make new friends diminishes it (Frison \& Eggermont, 2016; Yang \& Brown, 2013). Research has also highlighted the role of affect in SNS users' experience: amongst working age adults, 'negative' feelings (sadness, stress, anger) and 'positive' feelings (happiness) during SNS use were differentially associated with self-reported quality of life (Campisi, Folan, Diehl, Kable, \& Rademeyer, 2015). Amongst adults aged 50+, Hutto et al. (2015) found that 'directed communication', as opposed to 'passive consumption' on SNSs was associated with increased social satisfaction. In addition, use of the Internet for communication, but not information or commercial reasons, was associated with lower loneliness amongst adults aged 55+ (Sum, Mathews, Hughes, \& Campbell, 2008). However, owing to the small number of studies in older adults, as well as methodological limitations, the relationship between SNS use and wellbeing in later life remains unclear (Aarts, Peek, \& Wouters, 2014; Yu, McCammon, Ellison, \& Langa, 2016).

There is a small body of research in younger adults demonstrating a link between personality and different motives for SNS use, Internet use and social engagement. For example, conscientiousness has been found to correlate negatively with use of SNSs for self-presentation 
(i.e. expressing different aspects of the self) (Seidman, 2013). Studies of personality and affect in older adults have also indicated that individuals high in extraversion, conscientiousness, openness to experience, and agreeableness experience higher levels of positive affect, in contrast to individuals high in neuroticism who experience higher levels of negative affect (Kahlbaugh \& Huffman, 2017).

To better study SNS use, some studies have developed measures. However, the majority have been developed to gauge researchers' construct of interest without consideration of their psychometric properties (e.g. Frison \& Eggermont, 2016; Yang \& Brown, 2013). This has been highlighted as a general limitation of research in cyberpsychology, attributed to the field being in its infancy and the fast-paced nature of technological change (Howard \& Jayne, 2015). Of those having undergone more systematic psychometric development, measures are limited by a narrow focus on younger adult populations and a single SNS, Facebook (e.g. Bodroža and Jovanović, 2016). Given the evolving nature of technology, research beyond a single SNS is warranted. To obtain a better understanding of SNS use and its relationship to social wellbeing, valid and reliable measures are needed.

\section{Study aims}

The aims of the study were as follows:

(1) To develop a psychometrically robust measure to measure motives and affect associated with SNS use in older adults. These target constructs were chosen because research suggests that divergent motives and affect differentially affect wellbeing.

(2) To establish the psychometric properties of the measure, by analysing its factor structure, convergent validity, internal consistency and test-retest reliability. 
(3) To conduct preliminary analyses of the measure's relationship to loneliness and social isolation.

\section{$\underline{\text { Methods }}$}

\section{Overview}

This study was performed in collaboration with The Platform for Research Online investigating Cognition and Genetics in Aging (PROTECT), an online cohort study for the study of healthy brain ageing in adults aged 50+ (Huntley et al., 2018). Participants aged 65+ who had indicated that they used SNS in an earlier questionnaire $(n=2,884)$ were eligible to take part in the current study. An overview of the measure development process can be found in Figure 1. Informed by DeVellis (2003), the process was conducted in three stages: (1) initial development; (2) pilot study; and (3) empirical evaluation. 


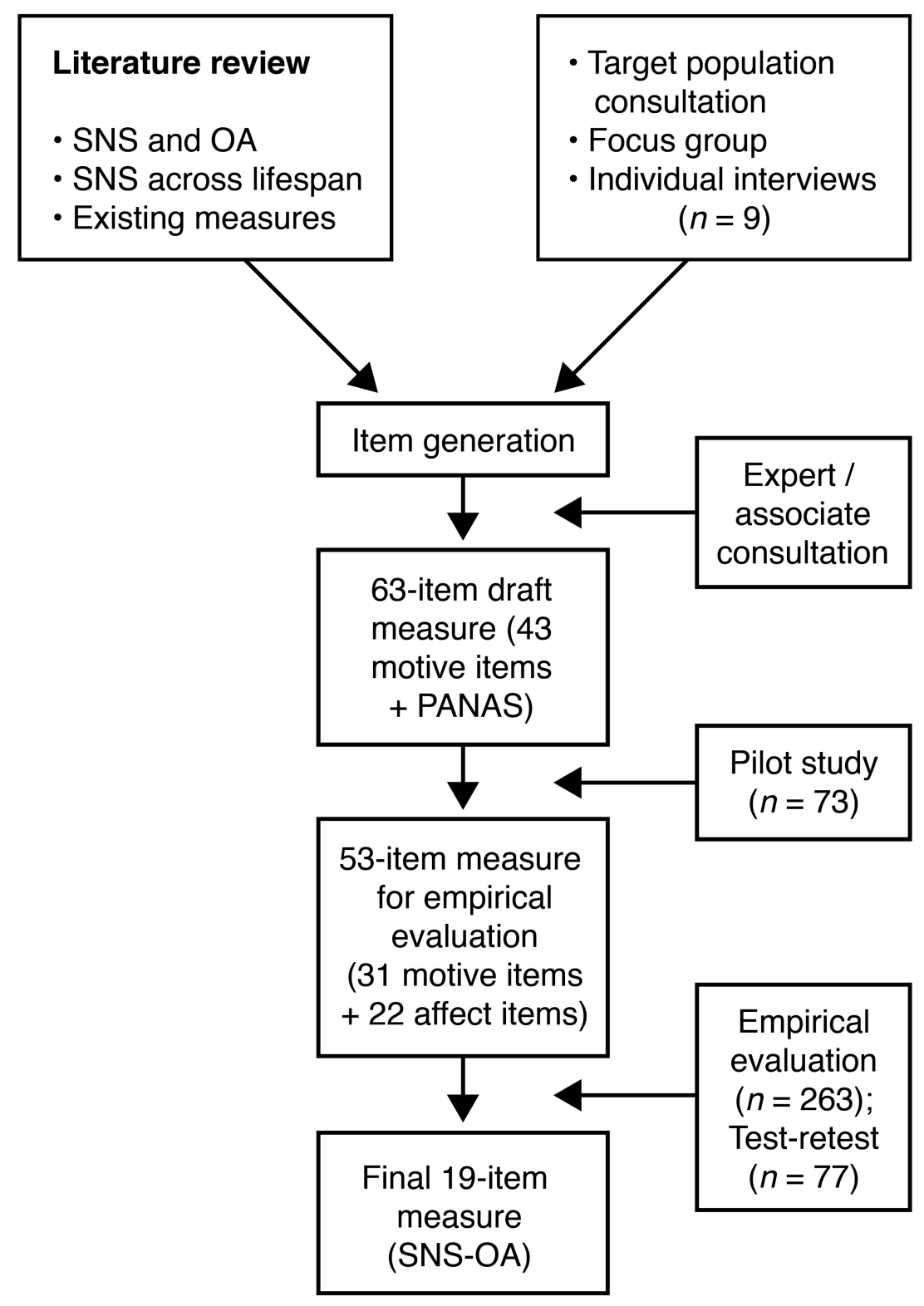

Figure 1.

SNS $=$ Social Networking Sites

$\mathrm{OA}=$ Older adults

PANAS = Positive and Negative Affect Scale ((Watson, Clark, \& Tellegen, 1988)

$\mathrm{SNS}-\mathrm{OA}=$ 'Social Networking Sites-Older Adults' measure 


\section{Initial Development}

Literature searches were performed of SNS use from an older adult perspective (aged 65+), motives for SNS use and existing SNS measures. Consultation with older adult SNS users (aged $65+)$, comprised of a focus group $(n=4)$ and individual interviews $(n=5)$, was conducted to canvas motives, attitudes and affect pertaining to SNS use. Subsequently, motives for SNS use were compiled and grouped into themes and refined based on informal consultations.

This process resulted in a draft measure with seven provisional motive themes or subscales; provisional because it was intended that the measure's structure would be determined by data-driven methods (i.e. Exploratory Factor Analysis), as well as by theory. The order in which items were presented across subscales was randomised. A 5-point Likert scale (not at all, a little, moderately, quite a bit, very much) was selected because it was appropriate for both sections of the scale (motives and affect), thereby reducing demand on participants.

Nine researchers from the field of SNSs, older adults and SNS measure development commented on the content, relevance and wording of the draft measure. Informal consultation ( $n$ =6) also took place to ensure the clarity and readability of the items.

\section{Pilot study}

A random sample of 90 participants from PROTECT were invited to complete the pilot measure over a two-week period (October 2017). All random selection took place by sorting participants according to their seven-digit ID number in Excel. Participants were also asked to provide qualitative feedback on the overall measure to further improve content validity. 


\section{Pilot study: Analytic plan}

Item variance and item means were examined, since it is desirable for items to have relatively high variance and for item means to be close to the centre of the range (DeVellis, 2003). For item reduction purposes, items with a standard deviation $(S D)<0.4$ were excluded (Schepers, Orrell, Shanahan, \& Spector, 2012). Items to which $>60 \%$ of participants responded 'not at all' were excluded as they were considered to lack content validity (Spector, Hebditch, Stoner, \& Gibbor, 2016). Cronbach $\alpha$ coefficients (internal consistency) and corrected item-scale correlations were inspected for individual subscales. Acceptable Cronbach $\alpha$ ranged from 0.7 to 0.94 (Terwee et al. 2007). Items with corrected item-scale correlations of $<0.3$ were excluded (Open University, 2018).

In response to qualitative feedback from participants that items were repetitive, associates of the corresponding author $(n=5)$ were asked to rate the similarity of items within subscales. Items were excluded if at least three respondents rated two items as highly similar. The item with the smallest value for Cronbach $\alpha$ if item deleted was retained (indicating better fit with the target construct).

\section{$\underline{\text { Main study }}$}

A random sample of 290 PROTECT participants were invited to take part in the main study over a one-month period (February 2018). Ninety respondents were randomly selected to complete the main measure one week later for the purpose of test-retest reliability. 


\section{Measures}

The Mini-International Personality Item Pool scale (Mini IPIP; Donnellan, Oswald, Baird, \& Lucas, 2006), a 20-item scale measuring the 'Big Five' factor model of personality, was used for the purpose of assessing convergent validity. It has acceptable reliability and validity, is brief and freely available (Cooper, Smillie, \& Corr, 2010; Donnellan et al., 2006). Although the Mini-IPIP has not been validated in an older adult sample, it has been observed to correlate with other 'Big Five' measures of personality used in studies with older adults (Donnellan et al., 2006).

The Cheek \& Buss (1981) Sociability Scale was used to measure sociability for the purpose of convergent validity. Sociability is a need or preference for affiliation with people. The sociability scale has adequate psychometric properties (Bruch, Gorsky, Collins, \& Berger, 1989; Cheek \& Buss, 1981), but is yet to be assessed within an older adult population.

The 20-item UCLA Loneliness scale (Version 3) was used to measure loneliness (Russell, 1996). It has good psychometric properties and has been validated in older adult populations (Russell, 1996).

A social isolation index was also administered (Shankar, McMunn, Banks, \& Steptoe, 2011), a composite of questions regarding marital/co-habiting status, frequency of social contact and membership of social groups.

\section{Analytic plan}

As with the pilot data, items with an $S D<0.4$ and with $>60 \%$ answering 'not at all' were removed. Data were inspected for multicollinearity and the sample size for Exploratory Factor Analysis (EFA) was checked for adequacy based on criteria by Terwee et al. (2007), recommending a sample size greater than seven multiplied by the number of items. 
An EFA using the extraction method 'principal axis factoring', recommended for nonnormally distributed data (Fabrigar et al. 1999), was conducted on the items with oblique rotation (direct oblimin). The Kaiser-Meyer-Olkin (KMO) measure of sampling adequacy was inspected, as well as for individual items, with acceptable values exceeding 0.5 (Field, 2013). Factor loadings $<0.4$ (explaining $<16 \%$ of the variance) were suppressed in the EFA (Stevens, 2002). Both theorydriven and data driven criterion for determining how many factors to extract were considered (Brown, 2009). Distribution (skewness and kurtosis) of total subscale scores were inspected. For the present sample size $(n=263)$, z-scores within the range \pm 3.29 were considered normally distributed (Kim, 2013).

\section{Reliability}

Reliability of subscales was measured by internal consistency (Cronbach's $\alpha$ coefficient) and testretest reliability using the Intra-Class Correlation Coefficient (ICC), with a two-way mixed effects model, absolute agreement and single measurement (Koo \& Li, 2016).

\section{Validity}

Convergent validity of subscales was assessed via the relationship of the 'SNS-OA measure' with related measures using Pearson $r$ correlations. The False Discovery Rate (FDR), set at the standard 5\% was employed to control for multiple tests (Benjamini \& Hochberg, 1995).

On the basis of prior research (e.g. Liu \& Campbell, 2017; Seidman, 2013), it was hypothesised that SNS use for the purpose of:

- Maintaining close ties (e.g. family and close friends) would correlate with extraversion, neuroticism, agreeableness, conscientiousness and sociability. 
- Maintaining weaker ties (e.g. casual friends, former friends, and acquaintances) would correlate with extraversion, neuroticism, intellect and sociability.

- Diversion (i.e. diverting one's attention) would correlate with extraversion, neuroticism and intellect, and negatively correlate with conscientiousness.

In addition, it was hypothesised that positive affect would correlate with extraversion, agreeableness, conscientiousness and intellect, and negative affect would correlate with neuroticism. On the basis of a small body of research (e.g. Buz, Pérez-Arechaederra, FernándezPulido \& Urchaga, 2015; Sum et al., 2008) it was hypothesised that loneliness would (1) negatively correlate with use of SNSs to maintain close and weaker ties, as well as positive affect; and (2) positively correlate with SNS use for the purpose of diversion, as well as negative affect. In addition, it was hypothesised that social isolation would negatively correlate with SNS use for the purpose of maintaining close and weaker ties.

For additional face and content validity, participants were asked to complete questions regarding how easy the measure was to complete, and the degree to which it enabled them to adequately represent motives and affect associated with SNS use. Participants could also indicate motives and affect perceived to be missing from the measure, as well as provide general qualitative feedback. 


\section{$\underline{\text { Results }}$}

\section{Initial Development}

Based on literature reviews and consultation with the target population $(n=9$; aged $66-89 ; 78 \%$ female) and a group of experts and associates, a pilot measure was compiled. The measure consisted of motives (43 items) and affect (20 items - see PANAS, below). Motive subscales reflected SNS use for the purpose of (1) maintaining close ties; (2) forming, maintaining and strengthening weaker ties; (3) self-expression (e.g. expressing one's identity, opinions and preferences); (4) connecting to local and global events; (5) learning and pursuit of interests; (6) diversion (diverting one's attention); (7) social surveillance (passively viewing others' content,

particularly that of 'weaker' connections). The number of subscale items varied between four and nine.

Based on research using the Positive and Negative Affect Scale (PANAS; Watson, Clark, \& Tellegen, 1988) to measure the emotional impact of SNS use in young adults (de Vries, Möller, Wieringa, Eigenraam \& Hamelink, 2017), the PANAS was selected to measure SNS affective experience. The PANAS has been validated in older adults (Buz et al., 2015), is sensitive to changes in external circumstances and can be used with short-term and longer-term instructions (Watson et al., 1988). For the purpose of the measure, instructions were adapted to reflect SNS use.

\section{Pilot study}

\section{Participants}

A total of 73 participants completed the pilot (response rate $82 \%$; mean age $=69.1$; range $65-84$ ). 


\section{Pilot study: Item reduction}

Eight items with an $S D$ of $<0.4$ and 17 items to which $<60 \%$ of participants responded 'not at all' were excluded, resulting in 38 items.

Many participants indicated that items were repetitive. Excluding items rated as highly similar by associates of the author left 30 items. Cronbach $\alpha$ were in the range of $0.8-0.94$ for all subscales with the exception of subscale 7 (social surveillance; $\alpha=0.54$ ), as only two items remained on this scale. These items were retained at this stage for content coverage. All item-scale correlations for subscales remained $>0.3$.

Nineteen of the remaining items had a mean of $<1.0$ (scale ranges from $0-4$ ). However, in order to maintain content coverage and because item-scale correlations coefficients were adequate (with $73 \%>0.6$, and all $>0.4$ ), these items were retained. On the basis of qualitative feedback, additional items were added to the measure for the empirical study (five motive and 17 affect items). This resulted in a final measure of 53 items (31 motive items grouped under seven subscales, and 22 affect items).

\section{$\underline{\text { Main study }}$}

263 participants were recruited (response rate $91.1 \%$; mean age $=70.8$; range $65-90$ ), the majority female $(80.2 \%)$, White British (93.5\%), married or co-habiting $(70.0 \%)$, retired $(87.8 \%)$ and educated to at least secondary level (Table 1). The test-retest group yielded 77 responses (response rate $85.6 \%)$. 


\section{Item properties}

The mean item score for the 53 items was $1.00(S D=0.48$; scale ranging $0-4)$. Cronbach $\alpha$ for the 53-item scale was 0.95, indicating marginal collinearity (Terwee et al., 2007). Analysis of item properties subsequently guided reduction of the number of items. One item with an $S D$ of $<0.4$ and ten items with $>60 \%$ of participants answering 'not at all' were excluded.

Eighteen of the items had a mean of $<1.00$, indicating that participants weakly endorsed many of the items. These items were retained for the sake of content coverage, and because including skewed items does not adversely affect the reliability of scales when internal consistency is high (Enders \& Bandalo, 1999). Mean item scores (i.e. on scale 0 - 4) retained in the final scale can be found in Table 3 . 
Table 1. Participant characteristics for empirical study $(n=263)$.

\begin{tabular}{|c|c|}
\hline Description & $n(\%)$ \\
\hline \multicolumn{2}{|l|}{ Age } \\
\hline Mean (range) & $65-90(70.8)$ \\
\hline $65-69$ & $128(48.7)$ \\
\hline $70-79$ & $125(47.5)$ \\
\hline $80+$ & $10(3.8)$ \\
\hline \multicolumn{2}{|l|}{ Gender } \\
\hline Female & $211(80.2)$ \\
\hline Male & $52(19.8)$ \\
\hline \multicolumn{2}{|l|}{ Marital Status } \\
\hline Married/Co-habiting & $184(70)$ \\
\hline Widowed & $39(14.8)$ \\
\hline Separated/Divorced & $31(11.7)$ \\
\hline Single & $9(3.4)$ \\
\hline \multicolumn{2}{|l|}{ Ethnic Origin } \\
\hline White British & $246(93.5)$ \\
\hline White European & $8(3)$ \\
\hline White Irish & $4(1.5)$ \\
\hline White Non-European & $2(0.8)$ \\
\hline Asian British: Indian & $2(0.8)$ \\
\hline Any other Asian British background & $1(0.4)$ \\
\hline \multicolumn{2}{|l|}{ Education Level } \\
\hline Undergraduate & $78(29.7)$ \\
\hline Vocational (e.g. Diploma) & $55(20.9)$ \\
\hline Secondary (GCSEs) & $48(18.3)$ \\
\hline Postgraduate & $37(14.1)$ \\
\hline Post-Secondary (College, A-Levels) & $32(12.2)$ \\
\hline Doctorate & $13(4.9)$ \\
\hline \multicolumn{2}{|l|}{ Employment Status } \\
\hline Retired & $231(87.8)$ \\
\hline Self-employed & $17(6.5)$ \\
\hline Employed (part-time) & $9(3.4)$ \\
\hline Employed (full-time) & $5(1.9)$ \\
\hline Unemployed & $1(0.4)$ \\
\hline
\end{tabular}


Factor structure (Exploratory Factor Analysis)

The determinant value for the correlation matrix of 42 variables indicated a problem with collinearity. An exploratory strategy was used to inspect the variables that were problematic (Field, 2013), resulting in exclusion of 19 items. The resulting 23 items were entered into an EFA. Based on criteria for retaining 'non-trivial' factors (those with a greater than three loadings of $>0.3$ ) (Brown, 2009), five factors were retained.

Correlations between factors exceeded 0.3 , warranting oblique rotation. The sample size was adequate $(7 \times 23=161)$. The $\mathrm{KMO}$ measure of sampling adequacy, as well as all $\mathrm{KMO}$ values for individual items, exceeded the acceptable limit of 0.5 , with the majority being greater than 0.8 . The five-factor solution after rotation accounted for $49.5 \%$ of the variance (Table 2). As variables that loaded $<0.4$ were suppressed, the final scale consisted of 19 items. The items that clustered on the same factor suggested that factor 1 represented 'maintain close ties', factor 2 represented 'maintain or strengthen weaker ties', factor 3 represented 'diversion', factor 4 represented 'positive affect' and factor 5 represented 'negative affect'. 
Table 2. Summary of the exploratory factor analysis for the SNS measure.

\begin{tabular}{|c|c|c|c|c|c|c|}
\hline \multirow[b]{2}{*}{ Item } & \multirow[b]{2}{*}{ Item description } & \multicolumn{5}{|c|}{ Rotated Factor Loadings } \\
\hline & & 1 & 2 & 3 & 4 & 5 \\
\hline 1 & To look at family or good friends' photos & 0.574 & 0.216 & 0.013 & 0.083 & -0.016 \\
\hline 2 & To share my news with family and good friends & 0.78 & -0.088 & 0.008 & -0.024 & 0.005 \\
\hline 3 & To know what family or good friends are up to & 0.548 & 0.151 & -0.042 & -0.042 & 0.006 \\
\hline 4 & To share things (e.g. articles, photos) with family or good friends & 0.682 & -0.127 & 0.177 & -0.023 & 0.05 \\
\hline 5 & To keep in touch with family or good friends & 0.775 & -0.051 & -0.063 & -0.066 & -0.106 \\
\hline 6 & To communicate with people I haven't seen in a while & 0.338 & 0.429 & 0.005 & -0.023 & -0.037 \\
\hline 7 & To stay connected with current or former work colleagues & 0.066 & 0.634 & 0.015 & 0.039 & -0.09 \\
\hline 8 & To reconnect with people I've lost contact with & 0.012 & 0.683 & 0.052 & -0.107 & 0.114 \\
\hline 9 & To browse around people I used to know & -0.12 & 0.785 & 0.013 & -0.084 & 0.051 \\
\hline 10 & To check out the posts (e.g. photos, links, notes) of people I used to know & -0.013 & 0.752 & 0.03 & 0.038 & 0.041 \\
\hline 11 & To pass the time when I'm bored & 0.017 & -0.036 & 0.775 & 0.042 & 0.037 \\
\hline 12 & To relax or unwind & -0.03 & 0.009 & 0.784 & -0.014 & -0.053 \\
\hline 13 & To keep myself occupied & -0.067 & -0.024 & 0.938 & 0.024 & -0.013 \\
\hline 14 & To update my profile and or status & 0.107 & 0.152 & 0.414 & -0.047 & -0.069 \\
\hline 15 & I feel alert when I use social media & -0.027 & -0.011 & -0.022 & -0.85 & 0.011 \\
\hline 16 & I feel attentive when I use social media & 0.008 & -0.053 & -0.075 & -0.881 & -0.102 \\
\hline 17 & I feel enriched when I use social media & 0.14 & 0.069 & 0.131 & -0.552 & -0.213 \\
\hline 18 & I feel irritated when I use social media & 0.008 & -0.048 & -0.011 & 0.047 & 0.619 \\
\hline 19 & I feel ambivalent when I use social media & -0.065 & 0.035 & -0.06 & 0.073 & 0.571 \\
\hline 20 & To keep up with changes in the way people communicate & 0.262 & 0.226 & 0.095 & -0.104 & 0.212 \\
\hline 21 & To connect with the local community & 0.09 & 0.165 & 0.149 & -0.145 & 0.334 \\
\hline 22 & To get information or answers to my questions & 0.249 & -0.013 & 0.164 & -0.183 & 0.193 \\
\hline \multirow[t]{3}{*}{23} & I feel amazed when I use social media & -0.019 & 0.16 & 0.106 & -0.369 & 0.162 \\
\hline & Eigenvalue & 6.71 & 2.29 & 1.83 & 1.60 & 1.29 \\
\hline & $\%$ of variance & 29.21 & 9.95 & 7.95 & 6.95 & 5.61 \\
\hline
\end{tabular}

Note.

$n=263$.

Factor loadings over 0.40 appear in bold.

Factors were interpreted as: $1=$ maintain close ties; $2=$ maintain and strengthen weaker ties; $3=$ diversion; $4=$ positive affect; $5=$ negative affect. 
Table 3. Item and subscale characteristics for the final 19-item scale.

\begin{tabular}{|c|c|c|c|c|c|c|c|}
\hline $\begin{array}{l}\text { Ite } \\
\text { m }\end{array}$ & Subscale & Item description $^{\mathrm{a}}$ & Item mean (SD) ${ }^{b}$ & $\begin{array}{l}\text { Subscal } \\
\text { e mean } \\
(\mathrm{SD})^{\mathrm{c}}\end{array}$ & $\begin{array}{l}\text { Mean total } \\
\text { score }(\mathrm{SD})^{\mathrm{d}}\end{array}$ & $\begin{array}{l}\text { Ske } \\
\text { w (z) }\end{array}$ & $\begin{array}{l}\text { Kurtosi } \\
\text { s (z) }\end{array}$ \\
\hline 1 & \multirow{5}{*}{$\begin{array}{l}1 . \\
\text { Maintain } \\
\text { close ties }\end{array}$} & To look at family or good friends' photos & $2.27(1.12)$ & \multirow{5}{*}{$\begin{array}{l}1.97 \\
(0.87)\end{array}$} & \multirow[t]{5}{*}{$9.86(4.36)$} & \multirow[t]{5}{*}{2.11} & \multirow[t]{5}{*}{-2.00} \\
\hline 2 & & To share my news with family and good friends & $1.71(1.18)$ & & & & \\
\hline 3 & & To know what family or good friends are up to & $2.06(1.16)$ & & & & \\
\hline 4 & & To share things (e.g. articles, photos) with family or good friends & $1.68(1.13)$ & & & & \\
\hline 5 & & To keep in touch with family or good friends & $2.14(1.12)$ & & & & \\
\hline 6 & \multirow{5}{*}{$\begin{array}{l}2 . \\
\text { Maintain, } \\
\text { strengthe } \\
\text { n weaker } \\
\text { ties }\end{array}$} & To communicate with people I haven't seen in a while & $1.72(1.06)$ & \multirow{5}{*}{$\begin{array}{l}0.92 \\
(0.66)\end{array}$} & \multirow[t]{5}{*}{$4.61(3.32)$} & \multirow[t]{5}{*}{8.65} & \multirow[t]{5}{*}{8.36} \\
\hline 7 & & To stay connected with current or former work colleagues & $1.03(0.97)$ & & & & \\
\hline 8 & & To reconnect with people I've lost contact with & $0.70(0.80)$ & & & & \\
\hline 9 & & To browse around people I used to know & $0.50(0.70)$ & & & & \\
\hline 10 & & To check out the posts (e.g. photos...) of people I used to know & $0.65(0.80)$ & & & & \\
\hline 11 & \multirow{4}{*}{$\begin{array}{l}3 . \\
\text { Diversion }\end{array}$} & To pass the time when I'm bored & $0.87(1.00)$ & \multirow{4}{*}{$\begin{array}{l}0.72 \\
(0.72)\end{array}$} & \multirow[t]{4}{*}{$2.89(2.88)$} & \multirow[t]{4}{*}{8.79} & \multirow[t]{4}{*}{6.43} \\
\hline 12 & & To relax or unwind & $0.89(1.03)$ & & & & \\
\hline 13 & & To keep myself occupied & $0.64(0.86)$ & & & & \\
\hline 14 & & To update my profile and or status & $0.48(0.64)$ & & & & \\
\hline 15 & \multirow{3}{*}{$\begin{array}{l}4 . \\
\text { Positive } \\
\text { affect }\end{array}$} & I feel alert when I use social media & $1.59(1.00)$ & \multirow{3}{*}{$\begin{array}{l}1.37 \\
(0.85)\end{array}$} & \multirow[t]{3}{*}{$4.13(2.54)$} & \multirow[t]{3}{*}{2.90} & \multirow[t]{3}{*}{-1.42} \\
\hline 16 & & I feel attentive when I use social media & $1.49(0.98)$ & & & & \\
\hline 17 & & I feel enriched when I use social media & $1.04(0.98)$ & & & & \\
\hline 18 & \multirow{2}{*}{$\begin{array}{l}5 . \\
\text { Negative } \\
\text { affect }\end{array}$} & I feel irritated when I use social media & $0.70(0.91)$ & \multirow{2}{*}{$\begin{array}{l}0.77 \\
(0.76)\end{array}$} & \multirow[t]{2}{*}{$1.54(1.52)$} & \multirow[t]{2}{*}{8.21} & \multirow[t]{2}{*}{6.11} \\
\hline 19 & & I feel ambivalent when I use social media & $0.83(0.90)$ & & & & \\
\hline
\end{tabular}

\section{Note.}

$n=263$

$\mathrm{a}=$ Motive items (items $1-14$ ) were prefixed with 'I use social media....'. b = Individual item scale score, ranging from $0-4$ ('not at all' to 'very much'). c = mean scale score on subscale, ranging from $0-4 . \mathrm{d}=$ mean sum of scores on a subscale. Possible total scores range are as follows: subscale $1(0-20)$, subscale $2(0-20)$, subscale $3(0-16)$, subscale $4(0-12)$, subscale $5(0-8)$. 
Table 4. Reliability statistics for the 19-item final scale.

\begin{tabular}{|c|c|c|c|c|c|c|}
\hline Item & Subscale & Item description $^{\mathrm{a}}$ & $\begin{array}{l}\text { Subscale } \\
\text { alphab }^{\text {b }}\end{array}$ & $\begin{array}{l}\text { Alpha }^{\mathrm{b}} \text { if } \\
\text { item } \\
\text { deleted }\end{array}$ & $\begin{array}{l}\text { Item-total } \\
\text { correlation }^{c}\end{array}$ & $\begin{array}{l}\text { Subscale ICC } \\
(95 \% \text { CI })\end{array}$ \\
\hline 1 & \multirow{5}{*}{$\begin{array}{l}\text { 1. Maintain } \\
\text { close ties }\end{array}$} & To look at family or good friends' photos & 0.82 & 0.80 & 0.59 & $0.75(.63-.83)$ \\
\hline 2 & & To share my news with family and good friends & & 0.78 & 0.65 & \\
\hline 3 & & To know what family or good friends are up to & & 0.80 & 0.56 & \\
\hline 4 & & To share things (e.g. articles, photos) with family or good friends & & 0.79 & 0.61 & \\
\hline 5 & & To keep in touch with family or good friends & & 0.77 & 0.67 & \\
\hline 6 & \multirow{5}{*}{$\begin{array}{l}\text { 2. Maintain \& } \\
\text { strengthen } \\
\text { weaker ties }\end{array}$} & To communicate with people I haven't seen in a while & 0.81 & 0.81 & 0.52 & $0.81(.72-.88)$ \\
\hline 7 & & To stay connected with current or former work colleagues & & 0.78 & 0.59 & \\
\hline 8 & & To reconnect with people I've lost contact with & & 0.75 & 0.69 & \\
\hline 9 & & To browse around people I used to know & & 0.77 & 0.66 & \\
\hline 10 & & To check out the posts (e.g. photos...) of people I used to know & & 0.77 & 0.62 & \\
\hline 11 & \multirow[t]{4}{*}{ 3. Diversion } & To pass the time when I'm bored & 0.82 & 0.76 & 0.69 & $0.79(.69-.86)$ \\
\hline 12 & & To relax or unwind & & 0.75 & 0.70 & \\
\hline 13 & & To keep myself occupied & & 0.71 & 0.78 & \\
\hline 14 & & To update my profile and or status & & 0.85 & 0.45 & \\
\hline 15 & \multirow{3}{*}{$\begin{array}{l}\text { 4. Positive } \\
\text { affect }\end{array}$} & I feel alert when I use social media & 0.82 & 0.72 & 0.71 & $0.74(.61-.83)$ \\
\hline 16 & & I feel attentive when I use social media & & 0.69 & 0.75 & \\
\hline 17 & & I feel enriched when I use social media & & 0.85 & 0.59 & \\
\hline 18 & \multirow{2}{*}{$\begin{array}{l}\text { 5. Negative } \\
\text { affect }\end{array}$} & I feel irritated when I use social media ${ }^{\mathrm{e}}$ & 0.59 & . & 0.42 & $0.65(.50-.76)$ \\
\hline 19 & & I feel ambivalent when I use social media ${ }^{\mathrm{e}}$ & & . & 0.42 & \\
\hline
\end{tabular}

\section{Note.}

$n=263$.

$\mathrm{a}=$ Motive items (items $1-14$ ) were prefixed with 'I use social media....' b $\mathrm{b}=$ Cronbach's alpha coefficient (internal consistency). $\mathrm{c}=$ Corrected (correlation of item with other subscale items, excluding itself). $\mathrm{d}=$ Intraclass Correlation Coefficient (test-retest reliability). ICC $<0.5=$ poor; $0.5-0.75=$ moderate; $0.75-$ $0.9=$ good; $>0.9=$ excellent $($ Koo \& Li, 2016). $\mathrm{e}=$ as only two items on the subscale, Cronbach's alpha if item deleted not applicable. 
Table 5. Pearson r correlations between subscales and loneliness, social isolation and personality traits..

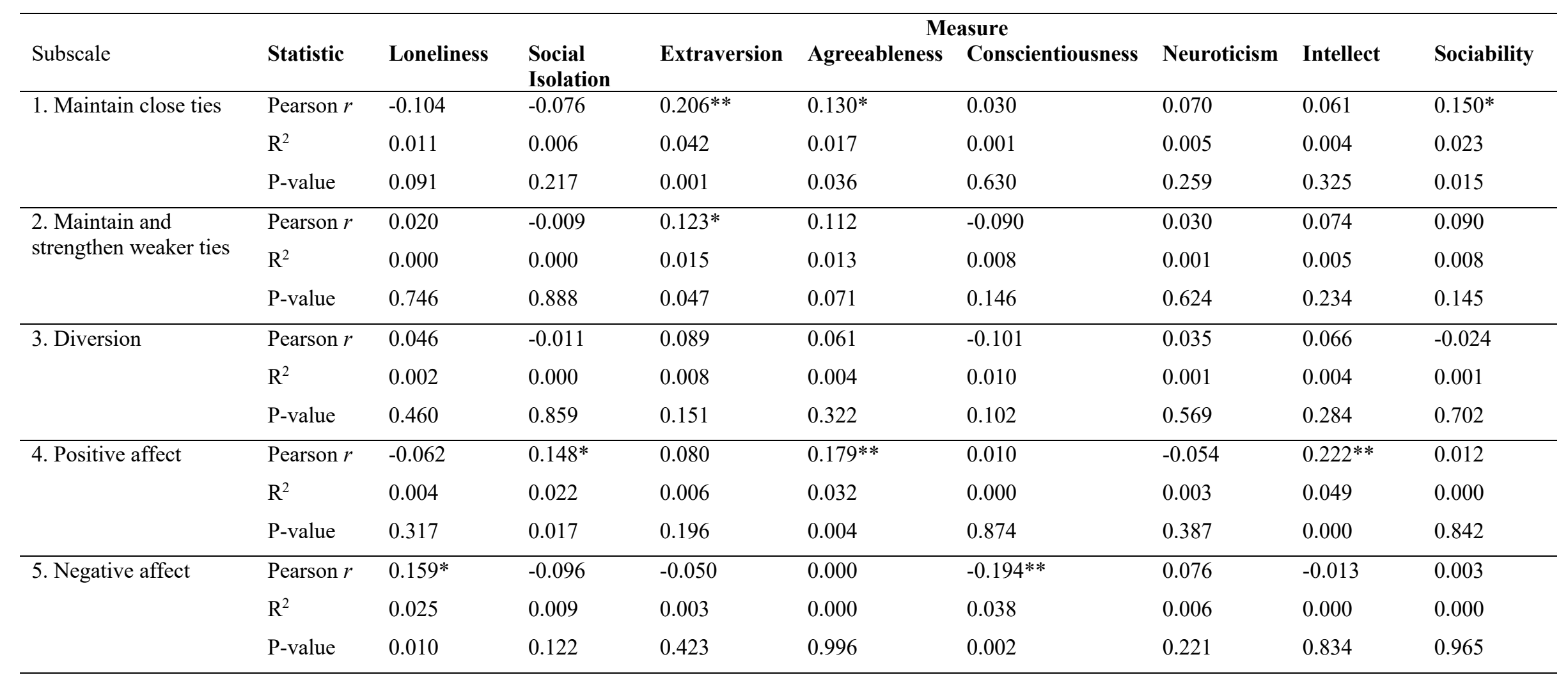

Note.

$n=263$.

Following measures were used: UCLA Loneliness Scale (Russell, 1996); Social Isolation Index (Shankar et al., 2011), Mini-IPIP (extraversion, agreeableness, conscientiousness, neuroticism, intellect) (Donnellan et al, 2006) and Sociability Scale (Cheek \& Buss, 1981).

$\mathrm{R}^{2}$ is proportion of total variance accounted for by correlation between two variables: $\pm 0.1=$ small; $\pm 0.3=$ medium; $\pm 0.5=1$ large.

*Significant at $\mathrm{p}<0.05$ (uncorrected threshold). ${ }^{*}$ Significant at corrected threshold (False Discovery Rate $=0.05$ ). 


\section{Refined measure properties}

The final 19-item scale had an overall mean scale score of $1.21(S D=0.51)$. Only two subscales demonstrated mean values close to the centre of the range $(0-4)$ and were normally distributed: maintain close ties $($ mean $=1.97 ; S D=0.87)$ and positive affect $($ mean $=1.37 ; S D=0.85)$. Remaining subscales were positively skewed and leptokurtic (peaked). See Table 3 for all measure properties.

\section{Reliability}

The final 19-item scale had a Cronbach $\alpha$ of 0.85 . Internal consistency for all subscales, with the exception of subscale 5 (negative affect: $\alpha=0.59$ ), was good, with Cronbach $\alpha$ ranging from 0.81 - 0.82 (see Table 4). All corrected item-total correlations exceeded 0.3, indicating good fit with the scale.

Regarding test-retest reliability, the ICC for all items $(n=53)$ was $0.85(\mathrm{~F}(76,76)=$ 12.32, $\mathrm{p}<0.001,95 \% \mathrm{CI}: 0.77$ to 0.90 .), indicating 'good to excellent' reliability (Koo \& Li, 2016). The ICC for the final 19-item measure was $0.82(\mathrm{~F}(76,76)=10, p<0.001,95 \% \mathrm{CI}: 0.73$ to 0.88 ), indicating 'moderate to good' reliability.

\section{Convergent Validity}

Results for Pearson $r$ correlations are displayed in Table 5. The hypotheses that using SNSs to maintain close ties would correlate with extraversion $(r=0.206, p=0.001)$; and that positive affect would correlate with agreeableness $(r=0.179, p=0.004)$, and intellect $(r=0.222, p=0.000)$, were supported in corrected analyses. There was also a negative correlation between negative 
affect and conscientiousness $(r=-0.194, p=0.002)$ after correction. Other hypotheses gained support in uncorrected analyses or gained no support (Table 5).

The mean social isolation score was $0.9(S D=0.95)$ and the mean loneliness score was $35.6(S D=11.1)$. The hypothesis that negative affect would correlate positively with loneliness was only supported in uncorrected analyses $(\mathrm{r}=0.159, p=0.010)$. Unexpectedly, positive affect correlated with social isolation in uncorrected analyses $(\mathrm{r}=0.148, p=0.017)$. All effect sizes $\left(\mathrm{R}^{2}\right)$ were small $(<0.1)$.

\section{Content and Face validity}

Overall, participants felt that the answers were relatively easy to answer (mean $=2.75, S D=0.85$; $0=$ very difficult, $4=$ very easy). In general, they indicated that the questionnaire enabled them to give a relatively 'true and complete picture' of their reasons for using SNSs (mean $=2.62, S D=$ 0.81 , and their feelings when using SNSs (mean $=2.46, S D=0.87 ; 0=$ not at all, $4=$ very much).

Seven participants commented that their SNS use was more nuanced than could be captured by the questionnaire (e.g. feelings might depend on what they see on SNSs). Twenty-two participants contextualised their SNS use by providing information about their communication practices, social and personal lives.

\section{$\underline{\text { Discussion }}$}

\section{$\underline{\text { Main findings }}$}

This study described the development of the 'SNS-OA measure' (Social Networking Sites - Older Adults), designed to capture motives and affect associated with SNS use in older adults. The final 
factor structure of the measure consisted of five subscales, which were interpreted as three motive scales: (1) maintain close ties, reflecting SNS use for the purpose of maintaining relationships with family and close friends; (2) strengthen and maintain weaker ties, reflecting SNS use for the purpose of maintaining and strengthening relationships with weaker ties such as casual friends or acquaintances; and (3) diversion, reflecting SNS use for the purpose of diverting one's attention. The remaining two scales were interpreted as: (4) positive affect, reflecting a pleasurable engagement with SNSs, and (5) negative affect (here comprised of feeling irritated or ambivalent), reflecting a level of psychological discomfort from using SNSs.

Convergent validity was demonstrated for subscales 1 and 4 (maintain close ties and positive affect), however other hypotheses regarding convergent validity either gained no support, or only gained support in uncorrected analyses. However, subscale 5 (negative affect) correlated negatively with conscientiousness in corrected analyses, in common with past research in young and middle-aged adults (Nunes et al. 2018). Content and face validity was sought via consultation with the target group, but some participants reported that their SNS use was more nuanced than could be represented by the questionnaire indicating limitations to face validity. Overall the measure demonstrated good test-retest reliability and internal consistency, with the exception of the negative affect subscale, which demonstrated inadequate internal consistency due to the small number of items on the scale $(n=2)$ (Tavakol \& Dennick, 2011).

\section{Relationship between SNS-OA measure and social wellbeing}

Loneliness was uncorrelated with all of the subscales after correction for multiple comparisons. This is in contrast to findings from young adults suggesting that SNS use for the purpose of maintaining friendships and socialising (Yang \& Brown, 2013), and in older adults, use of the 
Internet for communication purposes, was associated with lower loneliness (Sum et al., 2008). The absence of any association may be due to the relatively high levels of social wellbeing in the sample. This could be a sampling bias issue as it is possible that volunteers enrolled in cohort studies are particularly socially connected. Research indicating higher efficacy for interventions targeted at specific at-risk groups (Masi, Chen, Hawkley \& Cacioppo, 2011), suggests that SNSs could be particularly beneficial for individuals experiencing high levels of social isolation and loneliness.

Alternatively, it is possible that weaker associations between different SNS motives and social wellbeing exist for older adults. Evidence for the association between SNS use and social wellbeing amongst older adults is mixed and comes from a small number of studies (e.g. Aarts et al., 2014; Yu et al., 2016). Furthermore, past research has suggested that some older adults prefer telephone calls, email and written communication to SNSs, as they were perceived to afford deeper and more meaningful communication (Hope et al., 2014). However, these hypotheses need to be considered in light of the limitations of the measure.

\section{$\underline{\text { Methodological problems and limitations }}$}

Many items evoked low response variance, with items being weakly endorsed by participants, and three of the subscales were positively skewed due to low subscale mean scores. These results suggest that this sample used SNSs for a limited number of reasons (notably maintaining close ties, which had the highest mean scale score), and experienced a limited range and intensity of affect in response to SNS use. As such, it appears as though this older adult sample did not feel sufficiently strongly or divergently about SNSs to be captured meaningfully by this measure. Previous older adult research with non-SNS users has highlighted a lack of interest or perceived 
relevance as a common reason for not using SNSs (Hope et al., 2014; Quinn, Smith-Ray, \& Boulter, 2016). Incidentally, four participants commented that SNSs were not a particularly important part of their lives. This is in contrast to studies on younger adult SNS users, indicating a greater emotional impact of SNSs compared to their older counterparts (Hayes, van Stolk-Cooke, \& Muench, 2015).

The aim of this research was to develop a measure that was relevant to any SNS, however it was challenging to generate items that could apply broadly to all SNSs. Developing a measure specific to the most commonly used SNS (Facebook) was considered, however a general SNS measure was preferred because there are many similarities between different SNSs (Obar \& Wildman, 2015) and because a general SNS measure is more robust to the fast-changing nature of technological change. Nevertheless, there are limitations to treating all SNSs as the same, and this was reflected by participant feedback.

The majority of the sample was female, White British, and married or cohabiting. Only a minority of participants were aged $80+$. As such, results may obscure differences in SNS use according to gender, ethnicity, marital status and age. Given that factors associated with loneliness in later life include living alone and older age (Cohen-Mansfield, Hazan, Lerman, \& Shalom, 2016), findings here may not be relevant to those individuals at particular risk for loneliness and social isolation.

Effect sizes for the relationship between SNS use and personality were very small, suggesting that personality is a limited factor in SNS use for this older adult sample. Moreover, the vast majority of research on SNS use and personality has been conducted in younger adults. However, owing to the fact that this area of research is in its infancy, and the corresponding 
difficulties in identifying measures for convergent validity, it was determined that personality was the construct with the most relevance to the new scale.

Finally, a Confirmatory Factor Analysis (CFA) was not performed to verify the factor structure suggested by the EFA, both for practical reasons and because of concerns about the limitations of the measure.

\section{Implications for research}

Future research should explore whether attitudes towards SNSs represented here vary as a function of age. It is also possible that these attitudes are the result of cohort effects, due to the relatively low uptake of SNSs amongst this population compared to younger adults. Future research could explore this hypothesis by administering the 'SNS-OA measure' in middle-age and younger adults, as well as through the use of longitudinal designs.

Future research using the 'SNS-OA measure' should consist of a CFA to confirm factor structure and further convergent validity analyses to establish its validity.

It would be important to consider clinical, alongside statistical, significance in any examination of SNS use and social wellbeing. Pearson $r$ correlations between wellbeing measures, beyond being non-statistically significant, were very small. Correlations greater than 0.4 have been suggested as a threshold for clinical significance (Dunn, 2000). Even if future research were to demonstrate statistical significance between SNS use and outcomes, considering the degree to which this translates into real benefits for wellbeing is imperative.

As evidenced here, the relationship between SNS use and social wellbeing in older adults is complex. As such, future researchers should attempt to explore whether factors such as loneliness, social isolation, age, gender, marital status, functional impairment and domicile status 
are associated with differing motives for, and affect whilst, using SNS. These factors may have important implications for both loneliness and social isolation in older adults, and as such, it may be possible to use the SNS-OA measure to explore potential moderating relationships between these variables.

\section{Conclusions}

This study described the development of the 'SNS-OA measure', motivated by the proposal that psychometrically robust measures of SNS use are needed to understand its impact on social wellbeing. The measure demonstrated some adequate psychometric properties, although scores on items suggested that this cohort of older adults may not feel adequately strongly about SNSs to be meaningfully captured by a measure. Despite its limitations, this study was a first step towards capturing a more detailed understanding of SNS use in older adults. It has highlighted the challenges in developing a valid and reliable measure of SNS use in older adults, and in understanding its relationship to social wellbeing. 


\section{References}

Aarts, S., Peek, S. T. M., \& Wouters, E. J. M. (2014). The relation between social network site usage and loneliness and mental health in community-dwelling older adults. International Journal of Geriatric Psychiatry, 30, 942-949.

Benjamini, Y., \& Hochberg, Y. (1995). Controlling the false discovery rate: a practical and powerful approach to multiple testing. Journal of the Royal Statistical Society. Series B (Methodological), 57, 289-300.

Bodroža, B., \& Jovanović, T. (2016). Validation of the new scale for measuring behaviors of Facebook users: Psycho-Social Aspects of Facebook Use (PSAFU). Computers in Human Behavior, 54, 425-435.

Brown, J. D. (2009). Choosing the right number of components or factors in PCA and EFA. JALT Testing \& Evaluation SIG Newsletter, 13, 19-23.

Bruch, M. A., Gorsky, J. M., Collins, T. M., \& Berger, P. A. (1989). Shyness and sociability reexamined: a multicomponent analysis. Journal of Personality and Social Psychology, 57, 904.

Buz, J., Pérez-Arechaederra, D., Fernández-Pulido, R., \& Urchaga, D. (2015). Factorial structure and measurement invariance of the PANAS in Spanish older adults. The Spanish Journal of Psychology, 18, 1-11.

Campisi, J., Folan, D., Diehl, G., Kable, T., \& Rademeyer, C. (2015). Social media users have different experiences, motivations, and quality of life. Psychiatry Research, 228, 774-780.

Campos, W., Martinez, A., Sanchez, W., Estrada, H., Castro-Sánchez, N. A., \& Mujica, D. (2016). A systematic review of proposals for the social integration of elderly people using ambient intelligence and social networking sites. Cognitive Computation, 8, 529-542. 
Cheek, J. M., \& Buss, A. H. (1981). Shyness and sociability. Journal of Personality and Social Psychology, 41, 330-339.

Chipps, J., Jarvis, M. A., \& Ramlall, S. (2017). The effectiveness of e-Interventions on reducing social isolation in older persons: a systematic review of systematic reviews. Journal of Telemedicine and Telecare, 23, 817-827.

Cohen-Mansfield, J., Hazan, H., Lerman, Y., \& Shalom, V. (2016). Correlates and predictors of loneliness in older-adults: a review of quantitative results informed by qualitative insights. International Psychogeriatrics, 28, 557-576.

Cooper, A. J., Smillie, L. D., \& Corr, P. J. (2010). A confirmatory factor analysis of the Mini-IPIP five-factor model personality scale. Personality and Individual Differences, 48, 688-691.

de Vries, D. A., Möller, A. M., Wieringa, M. S., Eigenraam, A. W., \& Hamelink, K. (2017). Social comparison as the thief of joy: emotional consequences of viewing strangers' Instagram posts. Media Psychology, 21, 1-24.

DeVellis, R. F. (2003). Scale development: theory and applications (2 $2^{\text {nd }}$ ed.). USA: Sage.

Donnellan, M. B., Oswald, F. L., Baird, B. M., \& Lucas, R. E. (2006). The Mini-IPIP scales: tinyyet-effective measures of the Big Five factors of personality. Psychological Assessment, $18,192$.

Dunn, G. (2000). Statistics in Psychiatry. London: Wiley.

Dykstra, P. A. (2009). Older adult loneliness: myths and realities. European Journal of Ageing, 6, 91-100.

Enders, C. K., \& Bandalo, D. L. (1999). The effects of heterogeneous item distribution of item distributions on reliability. Applied Measurement in Education, 12, 133- 150. 
Fabrigar, L. R., Wegener, D. T., MacCallum, R. C., \& Strahan, E. J. (1999). Evaluating the use of exploratory factor analysis in psychological research. Psychological Methods, 4, 272-299.

Field, A. (2013). Discovering statistics using IBM SPSS statistics (4 ed.). London, England: Sage.

Frison, E., \& Eggermont, S. (2016). Exploring the relationships between different types of Facebook use, perceived online social support, and adolescents' depressed mood. Social Science Computer Review, 34, 153-171.

Hayes, M., van Stolk-Cooke, K., \& Muench, F. (2015). Understanding Facebook use and the psychological affects of use across generations. Computers in Human Behavior, 49, 507511.

Hope, A., Schwaba, T., \& Piper, A. M. (2014). Understanding digital and material social communications for older adults. Paper presented at the ACM CHI Conference on Human Factors in Computing Systems, Toronto, Canada.

Howard, M. C., \& Jayne, B. S. (2015). An analysis of more than 1,400 articles, 900 scales, and 17 years of research: The state of scales in cyberpsychology, behavior, and social networking. Cyberpsychology, Behavior, and Social Networking, 18, 181-187.

Huntley, J., Corbett, A., Wesnes, K., Brooker, H., Stenton, R., Hampshire, A., \& Ballard, C. (2018). Online assessment of risk factors for dementia and cognitive function in healthy adults. International Journal of Geriatric Psychiatry, 33, e286-e293.

Hutto, C. J., Bell, C., Farmer, S., Fausset, C., Harley, L., Nguyen, J., \& Fain, B. (2015). Social media gerontology: understanding social media usage among older adults. Web Intelligence, 13, 69-87.

Jung, E. H., \& Sundar, S. S. (2016). Senior citizens on Facebook: How do they interact and why? Computers in Human Behavior, 61, 27-35. 
Jung, E. H., Walden, J., Johnson, A. C., \& Sundar, S. S. (2017). Social networking in the aging context: Why older adults use or avoid Facebook. Telematics and Informatics, 34, 10711080.

Kahlbaugh, P., \& Huffman, L. (2017). Personality, Emotional Qualities of Leisure, and Subjective Well-Being in the Elderly. The International Journal of Aging and Human Development, $85,164-184$.

Kim, H.-Y. (2013). Statistical notes for clinical researchers: assessing normal distribution (2) using skewness and kurtosis. Restorative Dentistry \& Endodontics, 38, 52-54.

Koo, T. K., \& Li, M. Y. (2016). A guideline of selecting and reporting intraclass correlation coefficients for reliability research. Journal of Chiropractic Medicine, 15, 155-163.

Liu, D., \& Campbell, W. K. (2017). The Big Five personality traits, Big Two metatraits and social media: A meta-analysis. Journal of Research in Personality, 70, 229-240.

Lüders, M., \& Brandtzaeg, P. B. (2014). 'My children tell me it's so simple': A mixed-methods approach to understand older non-users' perceptions of Social Networking Sites. New Media \& Society, 19, 181-198.

Masi, C. M., Chen, H.-Y., Hawkley, L. C., \& Cacioppo, J. T. (2011). A meta-analysis of interventions to reduce loneliness. Personality and Social Psychology Review, 15, 219266.

Nunes, A., Limpo, T., Lima, C. F., \& Castro, S. L. (2018). Short scales for the assessment of personality traits: development and validation of the Portuguese Ten-Item Personality Inventory (TIPI). Frontiers in Psychology, 9, 461.

Obar, J. A., \& Wildman, S. (2015). Social Media Definition and the Governance Challenge: An Introduction to the Special Issue. Telecommunications Policy, 39, 745-750. 
OfCom. (2016). Adults' media use and attitudes report. London: OfCom. Retrieved from: https://www.ofcom.org.uk/research-and-data/media-literacy-research/adults/adultsmedia-use-and-attitudes

Quinn, K., Smith-Ray, R., \& Boulter, K. (2016). Concepts, Terms, and Mental Models: Everyday Challenges to Older Adult Social Media Adoption. Paper presented at the Second International Conference on Human Aspects of IT for the Aged Population, Toronto, Canada.

Russell, D. W. (1996). UCLA Loneliness Scale (Version 3): Reliability, validity, and factor structure. Journal of Personality Assessment, 66, 20-40.

Schepers, A. K., Orrell, M., Shanahan, N., \& Spector, A. (2012). Sense of competence in dementia care staff (SCIDS) scale: development, reliability, and validity. International Psychogeriatrics, 24, 1153-1162.

Seidman, G. (2013). Self-presentation and belonging on Facebook: How personality influences social media use and motivations. Personality and Individual Differences, 54, 402-407.

Shankar, A., McMunn, A., Banks, J., \& Steptoe, A. (2011). Loneliness, social isolation, and behavioral and biological health indicators in older adults. Health Psychology, 30, 377385.

Spector, A., Hebditch, M., Stoner, C. R., \& Gibbor, L. (2016). A biopsychosocial vignette for case conceptualization in dementia (VIG-Dem): development and pilot study. International Psychogeriatrics, 28, 1471-1480.

Stevens, J.P. (2002). Applied multivariate statistics for the social sciences $\left(4^{\text {th }}\right.$ ed.). Hillsdale, NJ: Erlbaum. 
Sum, S., Mathews, R. M., Hughes, I., \& Campbell, A. (2008). Internet use and loneliness in older adults. Cyberpsychology \& Behavior, 11, 208-211.

Tavakol, M., \& Dennick, R. (2011). Making sense of Cronbach's alpha. International Journal of Medical Education, 2, 53-55.

Terwee, C. B., Bot, S. D., de Boer, M. R., van der Windt, D. A., Knol, D. L., Dekker, J., Bouter, L.M. \& de Vet, H.C.W (2007). Quality criteria were proposed for measurement properties of health status questionnaires. Journal of Clinical Epidemiology, 60, 34-42.

Umberson, D., \& Montez, J. K. (2010). Social relationships and health: A flashpoint for health policy. Journal of Health and Social Behavior, 51, S54-S66.

Open University (2018). SPSS Statistics Tutorial. Retrieved from http://www.open.ac.uk/socialsciences/spsstutorial/files/tutorials/cronbachs-alpha.pdf

Victor, C. R., Scambler, S. J., Bowling, A. N. N., \& Bond, J. (2005). The prevalence of, and risk factors for, loneliness in later life: a survey of older people in Great Britain. Ageing \& Society, 25, 357-375.

Watson, D., Clark, L. A., \& Tellegen, A. (1988). Development and validation of brief measures of positive and negative affect: the PANAS scales. Journal of Personality and Social Psychology, 54, 1063-1070.

Yang, C.-c., \& Brown, B. B. (2013). Motives for using Facebook, patterns of Facebook activities, and late adolescents' social adjustment to college. Journal of Youth and Adolescence, 42, 403-416.

Yu, R. P., McCammon, R. J., Ellison, N. B., \& Langa, K. M. (2016). The relationships that matter: social network site use and social wellbeing among older adults in the United States of America. Ageing \& Society, 36, 1826-1852. 
